\title{
Queer Families and Mathematical Careers
}

\section{Corrin Clarkson}

For mathematicians in academia who identify as part of the LGBTQ community, there are certain choices that they need to consider when making career decisions which their heterosexual and cisgender colleagues will never have to face. These can include everything from how to comfortably introduce their partners at social gatherings, judiciously timing their choice to come out as queer ${ }^{1}$ while going through the tenure-track interview process, and signaling to queer students that they hope to be a resource regarding LGBTQ-related topics.

The January 15th panel Queer Families and Mathematical Careers held at the 2020 Joint Mathematics Meetings in Denver, CO, organized by Corrin Clarkson, Alex Hoover, and Alice Mark, discussed these and many other topics pertaining to queer mathematicians. ${ }^{2}$ The panel included five speakers:

\section{Amanda Folsom (AF) (she/her/hers)}

\section{Amherst College-Number Theory}

Family: I have been with my wife for about ten years, although we've been married for about half of that time. We also have a daughter who is almost three, so my daughter was not around when I was moving from my first

Corrin Clarkson (she/her/hers) is a clinical assistant professor at the Courant Institute of Mathematics, New York University. Her email address is clarkson@nyu. edu.

${ }^{1}$ The LGBTQ community includes people with a wide variety of sexual and gender identities. In recent years, the term "queer" has been used as an inclusive descriptor of members of this community.

2AWM-SPECTRA Panel: Queer Families and Mathematical Careers, organized by Corrin Clarkson, Alex Hoover, Alice Mark; 2020 Joint Mathematics Meetings, January 15-18, in Denver. Panel time slot Wednesday, January 15, 2:15-3:40 pm.

For permission to reprint this article, please contact: reprint-permission aams.org.

DOI: https://dx.doi.org/10.1090/noti2093 tenure-track job to my current job. But my wife was in the picture at that point.

\section{May Mei (MM) (she/her/hers) \\ Denison University-Dynamical Systems \\ and Mathematical Physics}

Family: When I was on the market, I had a second body. We weren't married because that wasn't legal yet, but that person was definitely coming with me.

\section{Chikako (Chika) Mese (CM) (she/her/hers)}

Johns Hopkins University-Geometric Analysis

Family: I have a wife. When I first came to Johns Hopkins we weren't married, but after marriage was legalized we got married. We have two twin girls, and they're currently in eighth grade.

\section{Dylan Thurston (DT) (he/him/his) \\ Indiana University-Topology, Geometry, \\ and Complex Dynamics}

Family: At the time I was searching for jobs, I was searching with my ex, Ken. He is also an academic, but is in computer science. We went through two job searches, one in Indiana and before that one in the New York area.

\section{Matt Voigt (MV) (he/him/his)}

San Diego State University-Mathematics Education Family: I'm a math education researcher. Currently, I'm a doctoral candidate on the job market, and my family includes myself and my partner of five years.

The following transcript has been edited for both clarity and brevity, and is printed here with the permission of the panelists. Every effort was made to preserve both the meaning and tone of all comments. 
How can you determine whether the colleges and universities where you are applying to teach are likely to be accepting of LGBTQ staff?

MM: Marriage wasn't legal yet when I was on the market, but that gave me a really good litmus test. I would look at same-sex benefits, or domestic partnership benefits.... Also, I'm childless and intend to stay so, but schools with good parental policies tend to be accepting. If they have people who advocate for these kinds of policies that's probably positive.

DT: Different schools do differ. I would try to talk to current graduate students at places you're applying to in order to try to gauge the climate at the individual schools.

Note: The Spectra Out and Ally Lists (http://1gbtmath .org/Peop 1e.htm 1 ) are useful resources for learning about the culture at a particular institution.

What are the family leave policies at your institutions?

MM: At [Denison University], if you've taught there for more than a year, you get a full semester of leave at pay or a full year at half-pay. That's for both having children by birth and by adoption.

CM: My current job [at Johns Hopkins] started in 2004, but even back then they had fairly liberal policies regarding partnership benefits. In fact, we used to have domestic partnership benefits. Once marriage got legalized, they got rid of that. And they had very generous financial help for adoptions. I'm not a biological mother, so they helped me adopt my children.

AF: At Amherst College, they're open with respect to birth or adoption - whether you are the biological parent or not. We have a few options that we can pick from.

When you are considering potential tenure-track positions, how do you figure out whether a school is located in an area that will be accepting of LGBTQ individuals? How does moving for an academic position affect your ability to find and sustain romantic relationships?

MV: When I started my graduate program I moved from Minnesota to California with my current husband of ten years. And that presented challenges in and of itself, even being in a stable relationship. Moving led to different emotional tolls.

DT: I'm in a long-term relationship now, but I met my current partner while I've been at Indiana. Bloomington, Indiana, is not a very large town, which has its own sort of issues. I met my partner and knew them for several years before we started dating, which was a week before they left the area. They only moved back later. It's tricky, people move away-like many academics you may well end up in a long-distance relationship for some amount of time.

Corrin Clarkson: I want to add that when you're on the job market and you're considering various locations and researching the policies of an institution and the political climate of the state, it's also perfectly legitimate to get on a dating app and look at what the dating scene is going to be like. Because if you're going to look for a partner there, you might as well check it out ahead of time.

DT: Another thing to keep in mind is that academic institutions tend to be in more accepting places than the rest of the state. Bloomington, for instance, is a little blue bubble in a red state. And Bloomington itself is quite open. For instance, there's a large trans population there.

When might you want to out yourself during an interview process? (And how can you make it less awkward if/when you choose to do so?)

CM: When I was looking for jobs and I went for interviews, I wasn't publicly telling them I'm gay. But once they offered me a job that's when you're in the driver's seat. So that's when I said, 'My partner blah blah blah', and I was very clear about my status.

MM: My wife and I were together all throughout graduate school, so I never felt like there was a specific moment when I had to out myself, since everyone just knew we were a couple. So I was talking with the supervisor at my summer VAP position, and it was the first time I had to-I didn't know how to say it. I had flown and my wife was driving the car with all of our stuff across the country, and somehow it just came out as, 'My car will be here next week.' I hadn't really thought concretely about what words I was going to use, and that was just how it came out.

How do you usually come out to your colleagues? How do you introduce your family to them?

MM: It's much easier to out yourself if you're in a relationship and you can just say, 'Here's my wife.' It's much more delicate if you were going to try to do that without a concrete person to point to.

DT: Our department has lots of social events involving families, often dessert parties for seminar speakers. It's a very friendly affair with many people's spouses, including my own when they have time to make it. I've never felt at all awkward about bringing my spouse with me. 
AF: We have a lot of social time in my department, so for me logistically how it happened was I showed up to the first event shortly after I was hired with my wife, and that was the end of it.

MV: I worked in industry for five years as a computer scientist. I think it was easier to come out in industry than it has been in academia. In industry, there's more of a personal feel, so it doesn't feel as irrelevant to talk about your partner or to bring them to things. Whereas in academia, I feel like there are these minimizing pressures of 'You're an academic, who you are doesn't matter. It's all about your work and what you can produce.'

DT: I would add that different departments have very different feels in terms of how it feels to bring up your family. When I was at Barnard College or Columbia, people talked much less about their families and their life in general outside of mathematics than they do at Indiana.

If you choose to be in an open relationship, how can you smoothly introduce multiple partners to your coworkers at social events?

MV: So mine was only in graduate school, so that was easier to navigate. I was in a younger crowd and brought multiple partners to different social events or my office. I don't know what that will look like in a more department setting.

DT: I am in a polyamorous relationship. I haven't really had to navigate it with the department because it's been a little theoretical. There isn't someone else besides my partner who I would want to bring to these events yet.

Are you out to your students? How can you signal to students that you want to be a resource for them to talk to about their LGBTQ-related life experiences?

AF: I don't stand up on the first day of class and make an announcement, but I have some things posted on the bulletin board outside my office that might indicate this if it's otherwise not obvious. I do things like I bring my daughter in to pass out our leftover Halloween candy, and that involves my wife coming in with my daughter. So I introduce them both to the class.

MV: I do come out to my students on the very first day and introduce them to who I am, my pronouns, my family, because I think that the representation is important. But also I have the privilege of being a gay man. I have privileges to be able to come out in those spaces that I think other queer people who maybe don't identify as a man may not.

DT: I also take a-well, a more low-key approach than you do-but along the lines of the ally signs and introducing myself with pronouns on the first day of class. Or maybe wearing certain t-shirts. But I do think that queer students are very attuned to these kinds of signals.

MV: Also, my research in math education is on queer students and their sense of belonging and inclusion in calculus. And role models and representation are one of the number one things that queer students talk about not having. When instructors have ally signs around or say things like, 'I have an antiharassment policy,' or 'I don't tolerate any discrimination,' students know that the instructor is going to be accepting. So even if we don't come out or don't feel comfortable, there's ways in which you can provide messaging to your students without it being out.

How can individuals and mathematics departments as a whole do a better job of supporting transexual, agendered, and other non-cisgendered undergraduate and graduate students?

MV: There are some examples of networking with O-STEM (Out and STEM), which is an undergraduate organization. I think that departments having partnerships with those tend to signal that they're going to be more accepting and try to understand that. And I also think professional development of faculty going through ally training as a department, as far as language use and pronoun use, can help.

DT: One thing that I've encountered is just getting my fellow faculty to correctly use pronouns. As I know you know, it's hard because they're older, they've used pronouns a certain way, and then things change. But, well, they're still smart people and they can still learn. And so we work on it. I wish it were faster.

MM: I think these programs are for you, so the question is, what do you want your administrator to do for you?

Note: There was also another relevant panel at the Joint Mathematics Meetings: Supporting Transgender and Non-binary Students. The January 18, 2020, panel was organized by Juliette Bruce, Christopher Goff, and Greg McCarthy.

How was the LG\&TBQ conference ${ }^{3}$ last June different from a typical math conference?

DT: It made me realize how little I had talked about personal life with some of the other mathematicians. Many of the people there were senior people that I had no idea were in that kind of community. In the mathematical talks, I felt like

\footnotetext{
${ }^{3}$ The LG\&TBQ conference was organized by Harrison Bray and Autumn Kent. It was held June 10-14, 2019, at the University of Michigan. More information at www. math. wi sc. edu/ kent/LG\&TBQ. htm7.
} 
people were making a better effort to reach out beyond their individual little area within that conference.

MM: There's this myth that we are brains in jars when we do math, that we're kind of disembodied and highly impersonal because we're on some sort of platonic frame where we're not people, when in fact that's totally false; we are people. That sounds stupid, but no, we are not theorems; we are people doing theorems. And that just became very clear in that space.

DT: Maybe it's related to being queer and trying to express yourself. I felt like the speakers were unusually good, and it just felt more connected than I usually feel at a math conference.

When applying to graduate schools as a female mathematician, what if you're afraid to come out for fear of being judged by conservative peers and facing additional harassment?

AF: It's true that there aren't as many women in math as men, and it's true that there are fewer queer people in general, but there are absolutely queer women in math. We have four of us up here on the stage. And so, I think just know that while it may very well be the case that certain institutions are maybe less supportive, or open, or tolerant, many are. There are lots of different kinds of schools and programs. Some advice that I give to my students when they're thinking about graduate programs-of course you're thinking about the math and things like that. But you can also think about things that are on the personal side. There are a lot. And talk to people if you can. If you have mentors at your institution now that you feel comfortable talking with, talk to them. Talk more with us. We can try to offer some more specific advice. And once you're at a place, there are lots of groups and organizations and people that I imagine you'll be able to find and connect with at a lot of places. There absolutely is community. It may take a little bit to find it or find yourself at the right place, but it is there.

MM: You have to navigate it how you want to navigate it. I'm not going to be here and be like, 'No! You do you! Leave those pins on!' You are doing you. You probably have a good sense of how out you want to be, what identities you want to present in which spaces-I'd say go with that. You don't have to perform any identity in any space that you don't want to. So if that's how you want to play it, then that's how you're going to play it. That's going to be fine. It's so deeply, deeply personal that you're just going to do whatever it is that you think is the right thing to do. And that's the closest metric to the right thing to do that there is. There is just no overarching guideline as to how you should play it.

$M V$ : We need to start viewing queerness as a strength. We are amazing people and see the world differently, and we can leverage that in our research and our mathematics; we have so much more value that we see the world differently, and so I think, 'Go us.'

Thanks to all five panelists for sharing positive stories of being included in the social life of their departments. These stories are important, because they show that many mathematicans are welcoming their LGBTQ colleagues with open arms. It is however also important to note that not everyone's story is positive. One participant who has a partner and small children and is a full professor at her university also spoke about department gatherings at her school. "People will get together with their kids and sometimes we're not invited, because there are several super conservative colleagues, so if they host something we are not invited. In my case, I definitely feel treated differently." The fear of being treated differently is the source of most of the questions discussed above, and unfortunately that fear is rooted in reality.

For many young queer mathematicians, there is often a great deal of anxiety around navigating the intersection of their identity as a mathematician and their identity as a queer person. This panel aimed to address these issues by giving queer mathematicians a space to share their stories and to recognize that they are not alone. But there are many more stories to be told and issues to be discussed. The organizers hope that this panel serves as part of a larger conversation that will be continued at future events for LGBTQ mathematicians. If you are interested in learning about such events, you are encouraged to join the Spectra mailing list at $1 \mathrm{gbtmath}$.org.

While LGBTQ events help to build safer spaces for queer mathematicians to learn from one another, it is also essential for the mathematics community as a whole to welcome and support its LGBTQ members. The work of building a welcoming and supporting community is too expansive to properly address here. One piece of that work is building awareness of the concerns faced by LGBTQ mathematicians. This article aims to do just that. Another piece of that work involves individuals acting as sources of information and support. Those who wish to make themselves available to LGBTQ mathematicans seeking support and guidance are encouraged to join the Spectra Out and Ally Lists (http: // 1gbtmath.org/People.htm7).

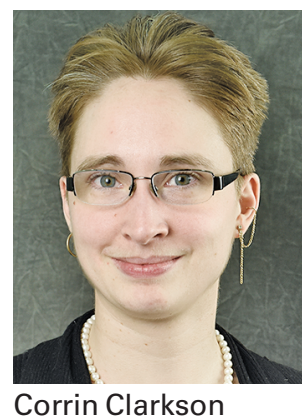

Credits

Author photo is by Laurie DeWitt, Pure Light Images. 